\title{
Research on the Integration of Vocal Music Education and Traditional Music in Colleges and Universities
}

\author{
Yu Tang \\ Aba Teachers University, Wenchuan, Sichuan, 623002
}

Keywords: vocal music education; traditional music; integration

\begin{abstract}
As the society continues to advance, the music teaching in Chinese colleges and universities is gradually becoming aware of the importance of traditional music teaching under the influence of globalization. This paper believes that college vocal music teachers should not only pay attention to the influence of Western music on Chinese college students, but also strengthen the popular education of Chinese traditional music and strengthen the popular education of Chinese traditional music based on the understanding of traditional Chinese culture to improve the overall quality of students.
\end{abstract}

\section{Introduction}

The music teaching in Chinese Colleges has made great progress, the quality of teachers has been significantly improved, and the teaching environment has also been improved compared to the past. College students can keep up with the teacher's ideas in their usual learning and have achieved good results in the music field. However, judging from the current situation, music teaching in Chinese Colleges still has certain drawbacks, and it is worth educators to think deeply. In concrete terms, most music classes in many Colleges are based on Western teaching methods. Students learn some Western theories and western knowledge systems, but they ignore the traditional Chinese teaching model. This makes some students understand little about traditional Chinese music and cannot form a complete learning system. To this end, in order to revitalize the traditional Chinese music culture, the primary issue is to transfer the relevant knowledge of traditional Chinese music to the students of music majors in contemporary Colleges so that students can enhance the inheritance and innovation of Chinese traditional culture in the process of learning traditional music [1].

\section{Traditional Music Culture and Status Quo of College Vocal Music Teaching}

With the continuous progress of society, people's demand for music culture is constantly changing. Since the 19th century, with the rapid development of European economy, European music has made great progress, and a large number of musicians have appeared, such as Beethoven and Bach. Many of the outstanding musical works created by these musicians have caused a stir in the music scene and are still respected by music lovers worldwide. As a result, European music spreads rapidly throughout the world and has the highest right to speak in music circles. Affected by the prevalence of European music, the vocal music teaching content, teaching methods, and teaching objectives of Chinese Colleges are gradually moving closer to Western music. In the process of vocal music teaching, the emphasis is on the use of European singing techniques and vocal techniques, ignoring the traditional music culture. importance. It can be seen that the impact of respecting the wave of European music is an important factor that causes the disconnect between traditional music culture and college vocal music teaching [2].

Since the 20th century, the process of global economic integration has accelerated and the world's three major music systems have gradually emerged in a convergent situation. However, our country's traditional music culture is in a weak position in the international context. From an international perspective, the recognition of the traditional music culture in China is relatively low, which in turn leads to the lack of Chinese traditional music culture in the right to speak. Over time, 
many vocal music educators in Colleges gradually formed the erroneous cognition that "traditional music culture is difficult to admire.” With the prevalence of European music, people's respect for the impact of European music has gradually increased, and this misperception has gradually taken root. It affects the choice of teaching methods in the actual teaching process and the focus of the teaching content [3]. It is precisely because our country's traditional music culture is in a weak position in the international context, so that more college vocal music learners overlook the importance of traditional music culture in college vocal music teaching, and then cause the inheritance and development of traditional music culture in our country. Negative Effects.

The lack of attention to the traditional music culture in Colleges is mainly reflected in two aspects: First, the setting of college vocal music teaching is difficult to reflect the importance of traditional music culture in China. The fundamental purpose of vocal music teaching is to cultivate talents. Through the explanation and guidance of excellent music works by teachers, students' inner feelings resonate with the ideas contained in music works, thus achieving the purpose of fostering sentiment, enhancing aesthetic taste and pursuing self-cultivation. Through vocal music teaching, students can master basic techniques such as singing and vocalization, which will lay a solid foundation for the learners to create more and better musical works in the future. Based on this vocal music teaching goal, teachers in the process of teaching music-related knowledge, pay more attention to the selection of music works with greater influence on the music, and the use of relevant materials for traditional music culture in our country is relatively low. Second, it is difficult to embody the importance of traditional music culture in our curriculum. The teaching curriculum of traditional music culture-related knowledge is relatively small in college vocal music teaching curriculum. Traditional music culture is only an elective course, not the main content of college vocal music teaching. In the actual teaching process, the proportion of teaching content such as national folk music, Chinese music history and masterpiece appreciation is low, resulting in a greater degree of arbitrariness in the study of traditional music culture and reducing students' exposure to traditional music culture. Opportunities have also affected the inheritance and development of our country’s traditional music culture.

\section{Characteristics of Traditional Music Culture}

In Chinese traditional music, "character is a positive character" is one of the most important features. In addition, China still has a lot of artistic characteristics as the main evaluation criteria. The reason why traditional Chinese art has such aesthetic requirements is mainly two levels of connotation. On the one hand, from a "character positive" point of view, the word is to enable the audience to understand the connotations of the performers throughout the entire process in the process of enjoying the music, specifically what the story is about, and what the performers are The emotions expressed; On the other hand, from the perspective of "circle", the performers are required to be clear. Only through the exquisite performances of the performers can enhance the appeal of the audience, allowing the audience to feel the unique charm brought about by traditional music in the atmosphere created by the performers. The "character" circle runs through the entire performance process. In the performance, "character" is the most basic training method. It not only enhances the performance level of performers, but also enhances the audience's experience and makes traditional music. More deeply rooted [4].

Traditional Chinese music has a long history. As early as in the Han Dynasty, some people have done research on the timbre of traditional music. The biggest difference between Chinese music and music in other countries is that the timbre in China pays more attention to the development of individuality; while the European vocal music emphasizes the organic combination of timbre and timbre and the integration of timbre. Because of this mutual integration, it is possible to enhance the sensation between the music and strengthen the correlation between the syllables through each other, and finally have a strong shock effect. This approach can make European music more attractive in its form of expression, forming a psychological resonance of the audience. However, traditional music in China is in stark contrast to traditional Chinese music, because Chinese traditional music attaches more importance to the addition of Chinese cultural elements and demonstrates the unique 
spiritual connotation of traditional music through the performance of singers, especially the importance of traditional musical timbres. More distinctive Chinese characteristics. Because Chinese people have been advocating the concept of "Golden Mean" in Confucianism since ancient times, they have mainly expressed implicitness and aestheticism in traditional music.

"Run cavity" plays a very important role in music because it can not only enhance the softness of music, but also enhance the overall momentum of music. Because in this perspective, the details of traditional music can be reflected, and through the control of the details, the unique charm of music can be enhanced, the traditional music can be developed, and the mood of the audience can be connected, and the work can show the expression of "different". The effect is to enhance the musical characteristics of traditional music. "Run cavity" belongs to the details of traditional Chinese music. "Understanders are busy and look inside the door." Under the premise of better control of details, it can enhance the audience's perception of traditional music, and thus enhance the inner motivation of music works. Therefore, the innovativeness of the "Run cavity" can enhance the audience's love for traditional music at a certain level.

\section{Measures for Integrating Traditional Music into Vocal Music Teaching in Colleges and Universities}

Although some Colleges have added traditional music and cultural related courses, they are too formal in the process of actual traditional music culture teaching and cannot help students to truly master the traditional knowledge of music culture. The basic reason is that the music teaching system does not pay attention to the traditional music culture and the vocal music education workers misunderstand the traditional music culture. In this way, vocal music educators pay too much attention to the education of western music in the process of actual vocal music teaching, while ignoring the teaching of relevant knowledge of traditional music culture. Therefore, the author believes that in order to truly promote the integration of traditional music culture into college vocal music teaching, we must first optimize the vocal music teaching system in Colleges, raise the emphasis on traditional music culture, change the understanding of vocal music teachers on traditional music culture, and add traditional music culture teaching courses. Innovative teaching methods. To enhance students' contact and understanding of traditional music culture-related knowledge, and to recognize our traditional music culture from the heart, and to conduct a deeper study on it.

The improvement of vocal music teachers' teaching ability is based on their own musical literacy and professional competence. Only vocal teachers with excellent professional knowledge and good professional qualities can show their strong teaching ability in the actual teaching process, thus forming a good teaching effect. Therefore, I believe that to promote the integration of traditional music culture and college vocal music teaching, first of all requires that vocal music teachers must have an in-depth and comprehensive understanding and understanding of traditional music culture. While our country's traditional music culture has a long history and rich content, vocal music teachers should pay attention to the deeper and more detailed research and analysis of traditional music culture in the actual teaching process and daily life, and gradually improve their professional qualities and professional capabilities. His own culture and music cultivation will provide guidance and reference for students to better learn traditional music culture [5].

College vocal music teachers should select appropriate teaching resources and materials according to the actual teaching content of traditional music culture in the actual vocal music teaching process, and choose appropriate teaching methods and means according to the actual teaching content differences. With the development of economy, information technology has been greatly improved, and some scientific and technological products have been gradually applied to the teaching of various subjects in Colleges. Such as: multimedia. Multimedia teaching can make abstract and boring learning content more intuitive and more vivid. Therefore, applying multimedia to the teaching of traditional music culture can effectively enhance students' interest in traditional music culture. The characteristics of multimedia integration, interactivity and multi-dimensionality can enable vocal music teachers to give full play to the role of teachers in the actual teaching 
process, promote two-way communication between teachers and students, and achieve personalized teaching, which will promote the individual development of students in vocal music. It is of great significance. Therefore, in the actual vocal music teaching process, teachers should actively and reasonably apply modern technology to the traditional music culture teaching, actively innovate the teaching model, help students find the fun and significance of the traditional music culture in the school, and improve the students' music cultivation and professionalism. Knowledge, at the same time, effectively promotes the inheritance and development of traditional music culture.

\section{Conclusion}

To improve the teaching quality of college music teaching, teachers, schools, and students need to work together to enhance understanding of traditional Chinese music and combine the essence of traditional music with the teaching system of Chinese universities. On the one hand, this helps to update at present, the concept of teaching in Colleges, on the other hand, plays a key role in the inheritance of traditional Chinese music culture. For this reason, the integration of traditional music elements in music teaching in Colleges requires the reform of the existing university teaching system, and it requires the education department to make firm information and do a good job of preparatory work.

\section{References}

[1] Zhao Yue. Analysis of the Integration of Traditional Music Culture in Vocal Music Teaching in Colleges [J]. Asia-Pacific Education, 2016(28).

[2] Zhou Ge, Li Qiaowei. On the integration of traditional music culture in college vocal music teaching [J]. Music Time,2016(6).

[3] Ruan Rongli. Analysis of the integration of traditional music culture in college vocal music teaching [J]. Zhengzhou Railway Occupation Technology College Journal, 2014(3).

[4] Zhou Xue. Research on Teaching Language in Vocal Music Teaching[J]. Journal of Hubei Institute of Adult Education, 2010(3).

[5] Wu Yasong. Analysis of the Status Quo and Development Approach of Vocal Music Teaching in Colleges [J]. Voice of the Yellow River, 2017(1). 